\title{
Modal pushover analysis on reinforced concrete arch bridge to estimate seismic responses
}

\author{
Lukman Murdiansyah, ${ }^{1, *}$, Robby Permata $^{2}$, and Donald Essen ${ }^{3}$ \\ ${ }^{1}$ Politeknik Negeri Padang, Jurusan Teknik Sipil, 25163 Padang, Indonesia \\ ${ }^{2}$ Universitas Bung Hatta, Jurusan Teknik Sipil, 25133 Padang, Indonesia \\ ${ }^{3}$ Universitas Mercubuana, Jurusan Teknik Sipil, 11650 Jakarta, Indonesia
}

\begin{abstract}
This paper presents an evaluation study of the performance of reinforced concrete arch bridge structures under earthquake load. The study is aimed to investigate the seismic performance of Wreksodiningrat Bridge, located in the province of Yogyakarta, Indonesia. This bridge is a three spans reinforced concrete arch bridge with a main span length of $75 \mathrm{~m}$ and two side spans with a length of $35 \mathrm{~m}$, respectively. This study is a part of a large project carried out by the Ministry of Public Works to study the impact of the new 2016 Indonesia Seismic Design Code for Bridges (SNI 2833:2016). The main objective of this paper is to determine the displacement demands due to earthquake load based on the new seismic code design for bridges, SNI 2833:2016. In addition, demand capacity ratios (D/C) of the main structural components, such as the compression arch and main column (pier) at the fixed support, are also reviewed in this paper. The analysis was carried out using nonlinear modal pushover analysis. The arch bridge modeling is three dimensional, where structural elements such as beams, columns, and compression arches are modeled as frame elements. The plastic hinges are modeled as fiber hinges with unconfined and confined concrete material stress-strain relationship following Mander formula. The analysis result shows that the displacement demands of the bridge are $2.9 \mathrm{~cm}$ and $20 \mathrm{~cm}$ in the longitudinal and transverse direction, respectively. The $\mathrm{D} / \mathrm{C}$ ratios of the compression arch due to demand earthquake load are 0.74 and 0.95 in the longitudinal and transverse direction of the bridge, while the $\mathrm{D} / \mathrm{C}$ ratios of the pier are 0.15 and 0.80 in the longitudinal and transverse direction. Based on the above results, it is concluded that the studied bridge is able to withstand the seismic load requirements in the new Indonesia Seismic Design Code.
\end{abstract}

\section{Introduction}

The need for performance evaluation of existing bridges against earthquake load has become an important issue in Indonesia lately. This evaluation is motivated by many new bridge constructions, on one side, and recent large magnitude earthquake events, which caused bridge damage, on the other side. In addition, Indonesia bridge seismic code has undergone three changes since 2002, the latter being SNI 2833:2016[1]. Therefore, it is necessary to evaluate the performance of bridge structures designed before SNI 2833:2016 is issued.

Two methods that quite often used to evaluate bridge performance under earthquake load are nonlinear time history analysis (NL-THA) and pushover analysis. Nonlinear time history analysis is the most rigorous to compute the seismic demand of the bridge. However, this analysis is time-consuming, and thus it is rarely used for seismic performance evaluation in Indonesia. Moreover, to carry out NL-THA, a sufficient number of suitable recorded and/or spectral match ground motions must be selected, which itself time-consuming.
Therefore pushover analysis is more often being employed to evaluate the seismic performance of bridges in Indonesia. Pushover analysis is well known because it has the advantage of detecting inelastic structural behavior and identifying the location of structural damage due to the formation of plastic hinges [2]. However, it should be noted that in pushover analysis, as found in the ATC 40 and FEMA 356 documents, these are not suitable to be used as a "tool" for bridge evaluation because these methods are limited by fundamental mode of the structure whereas, in the case of bridge structures, the structural response is quite often determined by higher modes. One of the developed methods using pushover analysis is Modal Pushover Analysis (MPA). Initially, this method has been developed to evaluate the inelastic responses of building structures $[3,4,5]$, but recently has been widely applied to bridge structures and compared to NL-THA method for its accuracy and it was concluded that MPA has a good degree of accuracy to predict inelastic responses of bridge structure against earthquake load $[6,7,8]$.

\footnotetext{
* Corresponding author: lukman@pnp.ac.id
} 


\section{Procedures of modal pushover analysis}

The MPA procedure used in this study is summarized as follows:

Step I: Perform the linear modal analysis to determine the natural periods, $T_{n}$, and mode shapes, $\phi_{n}$, of structure. Because the dynamic behavior of bridge structures is more complicated than the building structures, it is necessary to carry out the analysis with a large number of modes so that the higher mode effects are identified, and the modal mass participation ratio exceeds $90 \%$. However, a study conducted by Paraskeva et al. [6] has shown that there is little merit in adding modes whose modal mass participation ratio (MMPR) less than $1 \%$ and less rigid rules than the $90 \%$ that calibrated only for building. So in this study, modes that are considered to contribute only modes with MMPR higher than $1 \%$.

Step 2: For the $n$th mode, develop the base sheardeck displacement pushover curve, $V_{b}-u_{d n}$, for force distribution, $S_{n}^{*}=m \phi_{n}$, at control point, wherein $m$ is the mass matrix. A key issue in applying MPA for bridge performance evaluation is the selection of an appropriate control point to monitor the displacement demand. The choice of the control point location is generally chosen at the center mass of the deck and the top of the pier of a bridge.

Step 3: Idealized the pushover curve, $V_{b}-u_{d n}$, as a bilinear curve so that a yield point and ductility factor can be defined and then be used to appropriately reduce the elastic response spectra representing the seismic action considered for assessment of the bridge and convert the pushover curve corresponding to $n$th mode to the spectral acceleration, $S_{a}$, and spectral displacement, $S_{d}$, to an equivalent single degree of freedom system using relationship:

$$
\begin{gathered}
S_{a}=\frac{V_{b n}}{M_{n}^{*}} \\
S_{d}=\frac{u_{d n}}{\Gamma_{n} \phi_{d n}}
\end{gathered}
$$

Wherein, $\phi_{d n}$, is mode shape values at reference point for $n$th mode, $\Gamma_{n}$ is modal participation factor, $M_{n}^{*}$ is effective modal mass, and $u_{d n}$ is deck displacement values, for the $n$th mode.

Step 4: Calculate displacement demand at the monitoring point, in this study, by using the capacity spectrum method (CSM) based on elastic demand spectra [9].

Step 5: Step 1 to 4 are repeated for as many modes as required for sufficient accuracy. Since the displacement demand calculated in step 4 refers to the SDOF system, a correlation between displacement demand of the SDOF system to the actual bridge shall be made at this step. Hence, Step 5 consists of conversion of the displacement demand of the $n$th mode inelastic SDOF system to the peak displacement of the monitoring point, $u_{d n}$, of the bridge using Equation (2).

Step 6: Response quantities (displacement demands and plastic rotations) are obtained by combining the peak modal responses using the SRSS or CQC combination rule.

\section{MPA for evaluation of existing bridge}

\subsection{Description of the studied bridge}

The studied bridge is the Wreksodiningrat Bridge (see Fig.1). This bridge is a reinforced concrete arch bridge with a total length of $145 \mathrm{~m}$. The length of the mid-span is $75 \mathrm{~m}$, and both side spans are $35 \mathrm{~m}$. The deck system consists of 3 main girders and transverse beams. The total width of the bridge is $16.10 \mathrm{~m}$ and consists of two traffic lanes supported by three reinforced concrete arches. The height of the bridge is about $20 \mathrm{~m}$ from the ground. There are two main pier systems in this bridge, each of which consists of three pier legs. The pier system 1 located at STA $0+097$ has fixed support, and the pier system 2 located at STA $0+172$ has pinned supports.

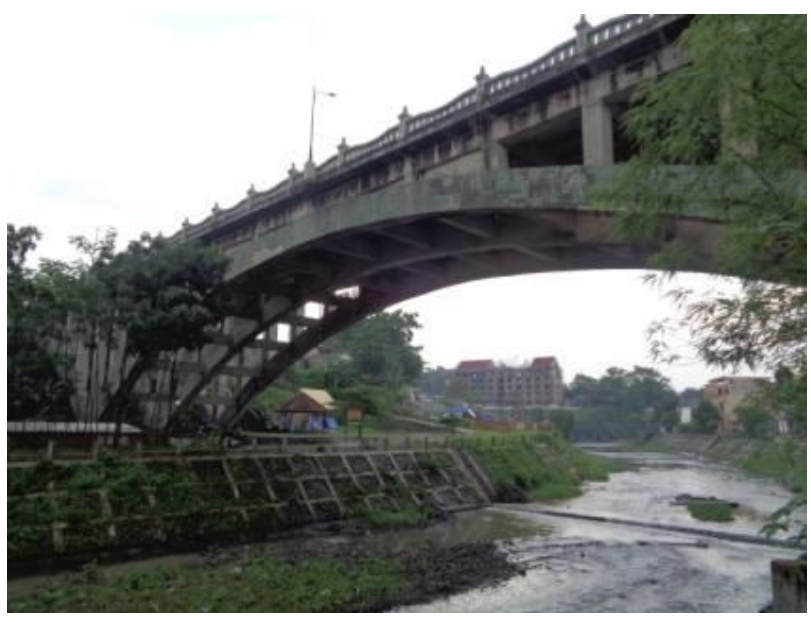

Fig. 1. Wreksodiningrat bridge.

Typical for this arch bridge type, the weight of the deck and the loads supported by the deck are transmitted to the arch members through the spandrel columns. In both abutments, the bridge freely moves in the longitudinal direction but is restrained in the transverse direction.

Due to the lack of soil investigation data and based on visual inspection at bridge location, in this study, the soil condition at bridge location is assumed to be medium class soil (site class D) based on SNI 2833:2016. For analysis purposes, the arch bridge modeling is three dimensional, where structural elements such as beams, columns, and compression arch are modeled as frame elements and deck slab as shell elements (see Fig.2). The soil-structure interactions in this study are neglected. The mass of the structure is assumed to be lumped at the joints with plastic hinges are assumed to occur at the bases and the ends of the 
pier, spandrel column, and girder members. The plastic hinges are modeled as fiber hinges with unconfined and confined concrete material stress-strain relationship following Mander formula [10, 11]. The structural responses to be evaluated are peak demand displacements in the longitudinal and transverse direction of the bridge subjected to seismic load requirement of SNI 2833:2016 at bridge location (see Fig.3). Demand capacity ratios of the pier system 1 and compression arches at the fixed support are also discussed in this study.

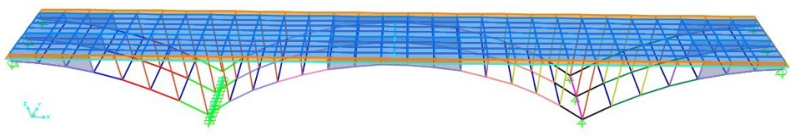

Fig. 2. 3D model of Wreksodiningrat Bridge.

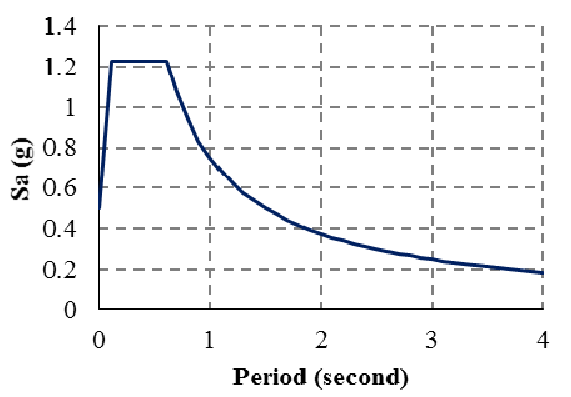

Fig. 3. Elastic response spectrum at the bridge location.

\subsection{Displacement demands}

As described earlier, the first stage of the MPA procedures is to determine the natural period, $T_{n}$, and mode shapes, $\phi_{n}$. In this study, 100 modes are enough to exceed 90\% MMPR. From 100 modes, the modes that affect the dynamic responses of the structure are selected based on the study by Paraskeva et al. [6], where the significant modes are the modes with MMPR value greater than $1 \%$.

Table 1 and Table 2 show the modes that influence the dynamic responses of the bridge. In the longitudinal direction of the bridge, there are 8 significant modes with the number of MMPR reaching $91.9 \%$, while in the transverse direction, there are 6 significant modes with the number of MMPR reaching $90.5 \%$.

Apart from determining the significant modes, one crucial issue in the MPA that also influences the accuracy of calculation of the peak displacement demand is the determination of the control point used as the reference point for developing the base shear vs deck displacement curves $\left(V_{b}-u_{d n}\right)$. It is necessary to use many control points to determine the displacement demand in bridge structures, because their behavior is more complicated when responding to earthquake load, and deck systems that cannot be assumed to be rigid diaphragm as in the floor of the buildings. Naturally, on the bridge structures, the control points are located on the deck and on the top of the piers. It is recommended to determine control points based on linear modal analysis. The nodes with maximum displacement obtained from linear modal analysis can be used as control points.

In this study, 3 control points are used, namely at the top of pier system 1 (CP1), in the middle of the main span (CP2), and the top of pier system 2, as shown in Figure 4 and Figure 5. CP1 and CP3 are used to develop the pushover curves in the longitudinal direction while $\mathrm{CP} 1, \mathrm{CP} 2$, and $\mathrm{CP} 3$ are used to develop the pushover curves in the transverse direction of the bridge.

Table 1. Significant modes in longitudinal direction

\begin{tabular}{|c|c|c|c|}
\hline Mode & $\begin{array}{c}\text { Period } \\
\text { (Second) }\end{array}$ & $\begin{array}{c}\text { MPF } \\
\text { (kN.m) }\end{array}$ & MMPR \\
\hline 2 & 0.555 & -49.779 & 0.297 \\
\hline 14 & 0.168 & 19.980 & 0.048 \\
\hline 21 & 0.128 & -26.772 & 0.086 \\
\hline 22 & 0.125 & -53.448 & 0.342 \\
\hline 24 & 0.118 & 22.942 & 0.063 \\
\hline 27 & 0.115 & 12.252 & 0.018 \\
\hline 28 & 0.113 & 21.552 & 0.056 \\
\hline 29 & 0.109 & -9.202 & 0.010 \\
\hline
\end{tabular}

Table 2. Significant modes in transverse direction

\begin{tabular}{|c|c|c|c|}
\hline Mode & $\begin{array}{c}\text { Period } \\
\text { Second }\end{array}$ & $\begin{array}{c}\text { MPF } \\
\text { kN.m }\end{array}$ & MMPR \\
\hline 1 & 0.845 & -76.205 & 0.697 \\
\hline 9 & 0.235 & 17.489 & 0.037 \\
\hline 10 & 0.223 & 18.427 & 0.041 \\
\hline 13 & 0.186 & -23.266 & 0.065 \\
\hline 42 & 0.077 & -17.819 & 0.038 \\
\hline 99 & 0.068 & 15.261 & 0.028 \\
\hline
\end{tabular}

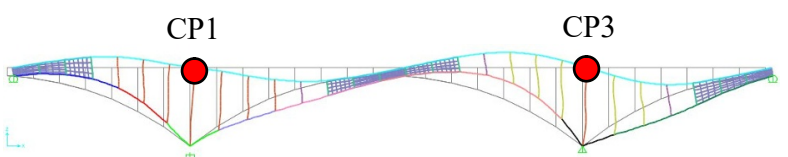

Fig. 4. Control point locations for MPA in the longitudinal direction.

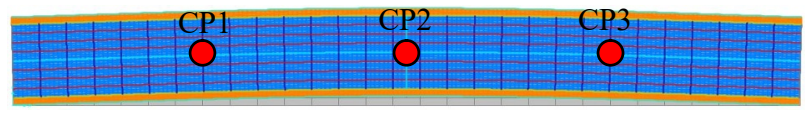

Fig. 5. Control point locations for MPA in transverse direction.

The modal load patterns, $S_{n}^{*}$, are calculated in each significant mode and applied to the structure so that the base shear force vs displacement curves (capacity curves) are obtained at each control point for each corresponding mode. The capacity curves are then converted into spectral acceleration, $S_{a}$, and spectral displacement, $S_{d}$, as shown in Fig 6 and Fig 7. Fig 6 and Fig 7 show the capacity curves for corresponding modes in the longitudinal and transverse direction, respectively. From Fig 6, it can be seen that the capacity curves of each mode intersect the demand curve in the 
proportional limit. Generally, it can be concluded that the bridge is still in the elastic range due to the earthquake load in the longitudinal direction. Fig 7 shows that only the 1 st mode capacity curve intersects the demand spectrum curve outside the proportional limit. This result indicates that the behavior of the bridge moves towards the inelastic range due to the earthquake load in the transverse direction.

The value of the displacement demand, $S_{d}$, for each of the significant modes is calculated using the capacity spectrum method, CSM [9]. By combining the demand displacement for $n$th mode, therefore the peak displacement demands of the bridge are obtained at each control point. The SRSS combination rule is used in this study. The displacement demands of the bridge in the longitudinal and transverse directions at each control point are summarized in Table 3 and Table 4.

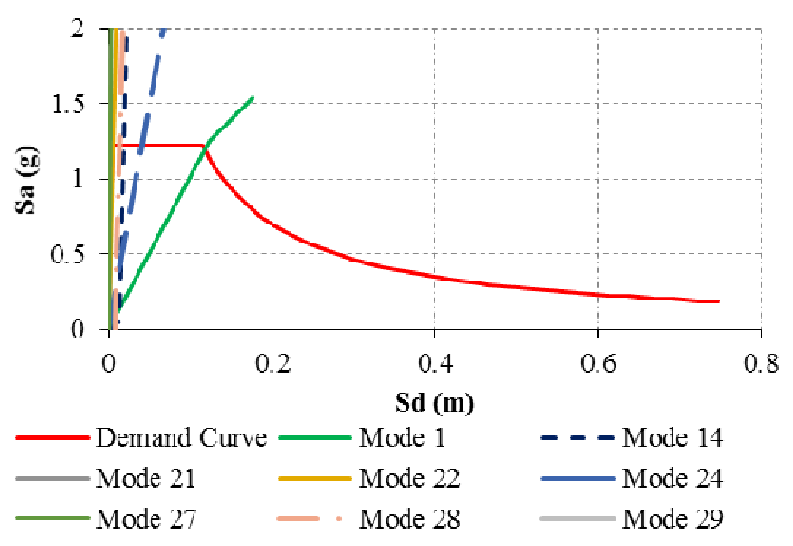

Fig. 6. Capacity curves at $\mathrm{CP} 1$ in the longitudinal direction.

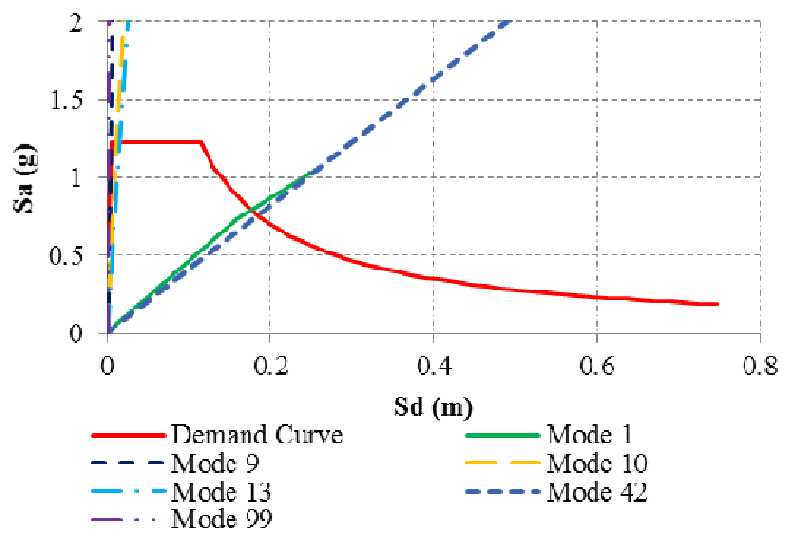

Fig. 7. Capacity curves at $\mathrm{CP} 2$ in transverse direction.

From Table 3 and Table 4, it can be seen that the fundamental mode has a dominant contribution to the bridge displacement demands, while higher modes have a relatively small effect, although the higher modes have MMPF value greater than $1 \%$. This result is due to the excited masses in the higher modes, which generally occur in the compression arch members, which trigger local mode, as shown in Fig 8.

Using the SRSS combination rule, the longitudinal displacement demands of the control points CP1 and $\mathrm{CP} 3$ are $2.6 \mathrm{~cm}$ and $2.9 \mathrm{~cm}$, respectively. While the displacement demands of the bridge in the transverse direction at the $\mathrm{CP} 1, \mathrm{CP} 2$, and $\mathrm{CP} 3$ are $13 \mathrm{~cm}, 20 \mathrm{~cm}$, and $13.5 \mathrm{~cm}$, respectively (see Fig 9).

Table 3. Displacement demands in longitudinal direction

\begin{tabular}{|c|c|c|c|}
\hline \multirow{2}{*}{ Mode } & \multirow{2}{*}{$\begin{array}{c}\text { Period } \\
\text { (Second) }\end{array}$} & \multicolumn{2}{|c|}{ Displacement Demands } \\
\cline { 3 - 4 } & 0.555 & 0.026 & 0.029 \\
\hline 2 & $\mathbf{C P 1}(\mathbf{m})$ & CP3 (m) \\
\hline 14 & 0.168 & 0.000 & 0.001 \\
\hline 21 & 0.128 & - & - \\
\hline 22 & 0.125 & 0.002 & 0.002 \\
\hline 24 & 0.118 & 0.000 & 0.000 \\
\hline 27 & 0.115 & - & - \\
\hline 28 & 0.113 & 0.001 & - \\
\hline 29 & 0.109 & - & - \\
\hline \multicolumn{2}{|c|}{ SRSS } & 0.026 & 0.029 \\
\hline
\end{tabular}

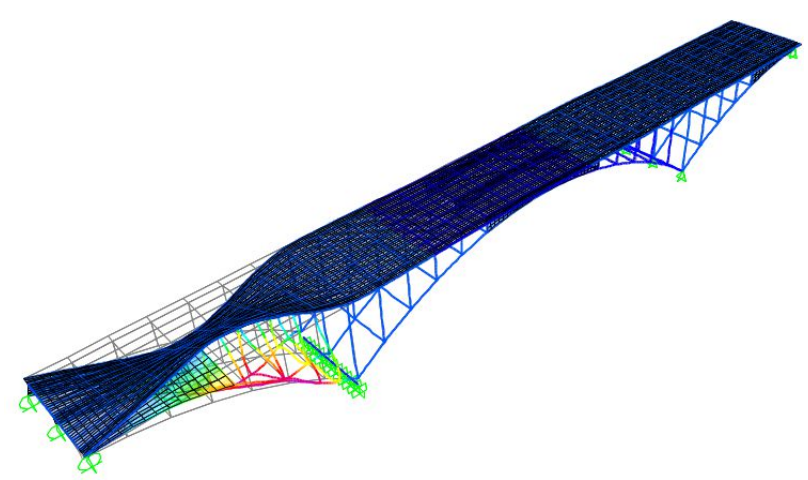

Fig. 8. Local mode (10th mode) due to excited masses at compression arch members.

Table 4. Displacement demands in transverse direction

\begin{tabular}{|c|c|c|c|c|}
\hline \multirow{2}{*}{ Mode } & \multirow{2}{*}{$\begin{array}{c}\text { Period } \\
\text { (Second) }\end{array}$} & \multicolumn{3}{|c|}{ Displacement Demands } \\
\cline { 3 - 5 } & CP1 (m) & CP2 (m) & CP3 (m) \\
\hline 1 & 0.845 & 0.130 & 0.200 & 0.135 \\
\hline 9 & 0.235 & - & - & - \\
\hline 10 & 0.223 & - & - & - \\
\hline 13 & 0.186 & 0.002 & 0.002 & 0.002 \\
\hline 42 & 0.077 & 0.000 & 0.000 & 0.000 \\
\hline 99 & 0.068 & - & - & - \\
\hline \multicolumn{7}{|c|}{ SRSS } & 0.130 & 0.200 & 0.135 \\
\hline
\end{tabular}

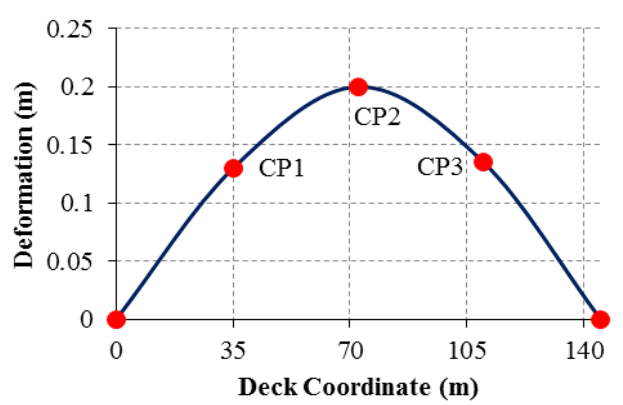

Fig. 9. Displacement of Wreksodiningrat Bridge in the transverse direction. 


\subsection{Element forces}

Until now, the determination of the internal forces in structural elements using MPA is still discussed rarely. The method for internal force calculations (moment, shear, and axial force) using the MPA is developed by Goel and Chopra [4]. However, this method is only applied to buildings. In this study, the internal forces of interest members are determined based on the peak displacement demand value for simplicity. The internal force calculations of structural members are carried out based on the following stages:

Step I: After peak demand displacements of the bridge are obtained using SRSS combination, plot the internal force curves of the element of interest due to the pushover load in the corresponding mode vs. displacement at the monitoring point.

Step 2: Determine the peak modal internal forces (peak modal moment, peak modal shear force, and peak modal axial force) for each mode based on the value of peak displacement demand of the structure.

Step 3: Calculate the peak element forces (peak moment, peak shear, and peak axial force) of the element of interest by combining the internal forces of each mode obtained in step 2 using the SRSS combination rule.

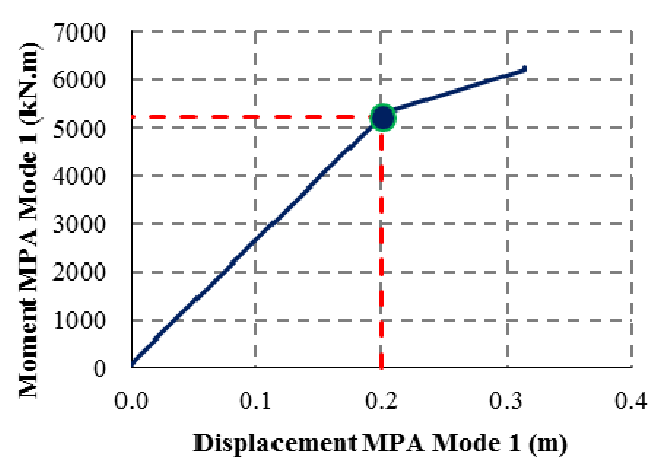

Fig. 10. Internal force (moment) calculation for the pier at fixed support.

For example, Fig 10 shows the calculation example for pier moments of pier system 1 due to the modal load of the 1st mode. The curve shown in Fig 10 is the curve of moment of the pier at fixed support due to modal load of 1st mode (y-axis) vs displacement of the structure at the control point CP2 due to modal load of 1 st mode (xaxis). The internal force (moment) in this mode is determined by plotting the value of the peak displacement demand, which is $20 \mathrm{~cm}$, on the curve. The corresponding moment with the peak displacement demand is the moment for the structural element of interest due to the modal load of 1 st mode. Do the same way to obtain the moment and shear force due to the modal load of the other modes. Specifically for axial force, axial force is obtained by combining the peak modal axis forces and due to gravity load using the SRSS combination rule [4].

In this study, the evaluated bridge members are the piers and compression arches of the middle frame at the fixed support, as shown in Fig 11.

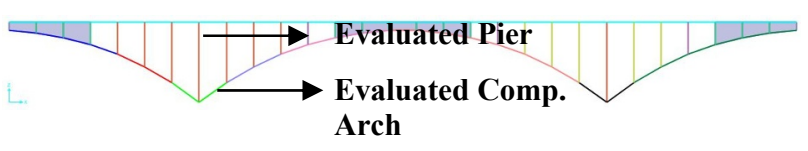

Fig. 11. Evaluated members

Table 5. Internal forces in the compression arch due to earthquake load in the longitudinal direction

\begin{tabular}{|c|c|c|c|c|c|}
\hline Mode & $\begin{array}{l}\text { Periode } \\
\text { (Second) }\end{array}$ & $\begin{array}{c}\text { Moment } \\
\text { (kN.m) }\end{array}$ & $\begin{array}{c}\text { Shear } \\
(\mathrm{kN})\end{array}$ & $\begin{array}{c}\text { Axial } \\
(\mathbf{k N})\end{array}$ & $\begin{array}{c}\text { Gravity } \\
(\mathrm{kN})\end{array}$ \\
\hline 2 & 0.555 & 14996 & 2287 & 283 & \multirow{8}{*}{11215} \\
\hline 14 & 0.168 & 2168 & 477 & -20 & \\
\hline 21 & 0.128 & - & - & - & \\
\hline 22 & 0.125 & 462 & 110 & 4189 & \\
\hline 24 & 0.118 & 607 & 85 & -146 & \\
\hline 27 & 0.115 & - & - & - & \\
\hline 28 & 0.113 & 1631 & 236 & -1293 & \\
\hline 29 & 0.109 & - & - & - & \\
\hline \multicolumn{2}{|c|}{ SRSS } & 15259 & 2352 & \multicolumn{2}{|c|}{12045} \\
\hline
\end{tabular}

Table 6. Internal forces in the pier due to earthquake load in the transverse direction

\begin{tabular}{|c|c|c|c|c|c|}
\hline Mode & $\begin{array}{l}\text { Periode } \\
\text { (Second) }\end{array}$ & $\begin{array}{c}\text { Moment } \\
\text { (kN.m) }\end{array}$ & $\begin{array}{c}\text { Shear } \\
(\mathbf{k N})\end{array}$ & $\begin{array}{c}\text { Axial } \\
(\mathbf{k N})\end{array}$ & $\begin{array}{c}\text { Gravity } \\
(\mathrm{kN})\end{array}$ \\
\hline 1 & 0.845 & 5233 & 573 & 2086 & \multirow{6}{*}{1412} \\
\hline 9 & 0.235 & - & - & - & \\
\hline 10 & 0.223 & - & - & - & \\
\hline 13 & 0.186 & 150 & 25 & 93 & \\
\hline 42 & 0.077 & 74 & 15 & 253 & \\
\hline 99 & 0.068 & - & - & - & \\
\hline \multicolumn{2}{|c|}{ SRSS } & 5236 & 574 & \multicolumn{2}{|c|}{2533} \\
\hline
\end{tabular}

Table 5 and Table 6 show the calculation of peak internal forces of arch compression (in the longitudinal direction) and of the pier (in the transverse direction) obtained by using the SRSS combination rule. From the tables, it can be seen that internal forces of higher modes have a considerable effect on the peak member forces, and this is in contrast to the case of displacement discussed earlier. By plotting internal forces (moment, axial force) of the evaluated members into P-M interaction diagrams, the demand capacity ratios of pier and compression arch elements will be obtained. The interaction diagrams for the evaluated members are shown in Fig 12 to Fig 15.

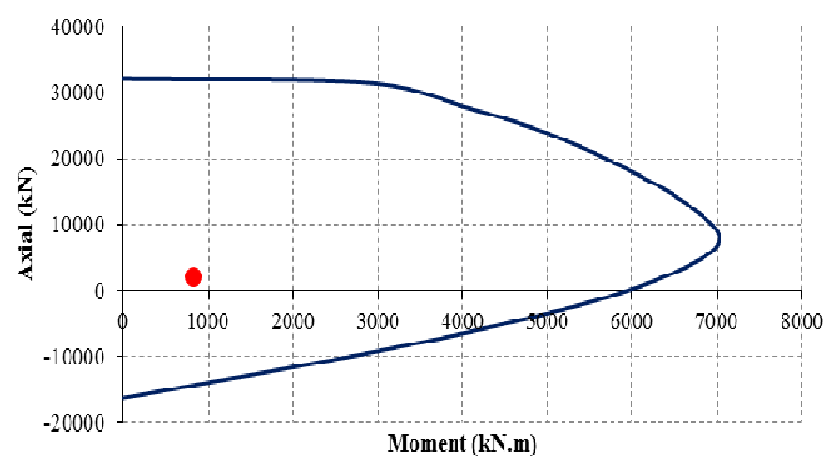

Fig. 12. P-M3 Interaction diagram of evaluated pier in the longitudinal direction 


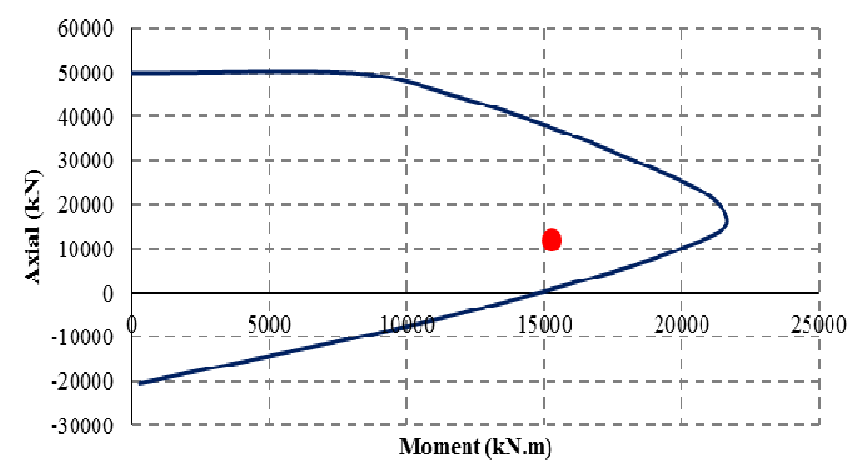

Fig. 13. P-M3 Interaction diagram of evaluated compression arch in the longitudinal direction

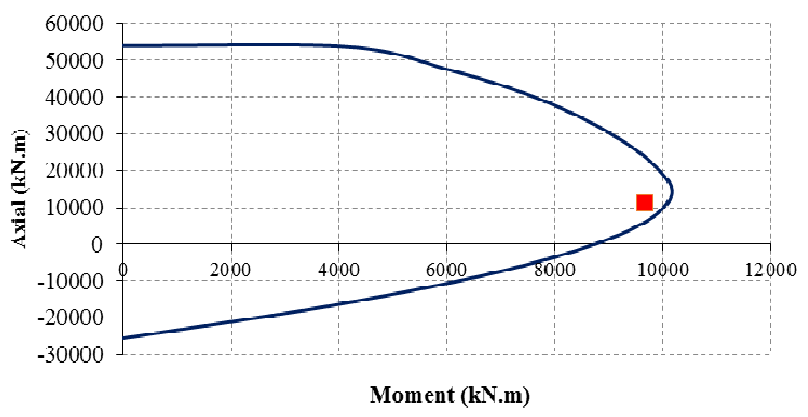

Fig. 14. P-M2 interaction diagram of evaluated compression arch in the transverse direction

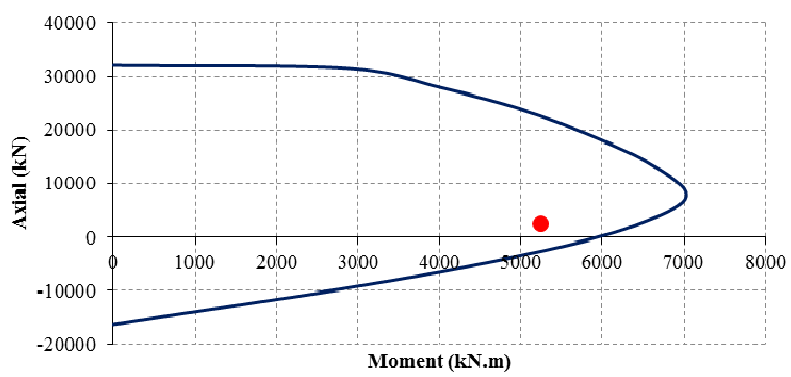

Fig. 15. P-M2 interaction diagram of evaluated pier in the transverse direction

From the interaction diagrams above, it can be seen that the main structural components at fixed support are capable of carrying earthquake load requirements in the new SNI 2833:2016, both in the longitudinal and transverse direction. The demand capacity ratios of the pier are 0.15 in the longitudinal direction and 0.80 in the transverse direction. Meanwhile, the demand capacity ratio of the compression arch is 0.74 in the longitudinal direction and 0.95 in the transverse direction.

\section{Conclusions}

From the MPA study conducted on the Wreksodiningrat Bridge, the following conclusions are drawn:

1. The maximum displacement demands of the new SNI 2833:2016 earthquake load in the longitudinal and the transverse directions are $2.9 \mathrm{~cm}$ and $20 \mathrm{~cm}$, respectively.

2. Higher mode contributions to demand displacement of the bridge are small.

3. The main structural members (piers and compression arches) at fixed support are able to carry earthquake load requirements in the new SNI 2833:2016, both in the transverse and in the longitudinal direction.

4. In calculating internal forces using MPA, higher modes have a considerable effect on the structural member internal forces.

\section{References}

1. SNI3 2833:2016. Planning Earthquake Resistance for Bridges.

2. H. Krawinkler, G.D.P.K Seneviratna. Engg. Struc. 20(4-6), 452-464 (1998)

3. A.K. Chopra, R.K. Goel. Earthq. Eng Struct Dyn. 31(3), 561-582 (2002)

4. R.K. Goel, A.K. Chopra. Earthq. Spec. 21(1), 125139 (2004)

5. A.K. Chopra, R.K. Goel. Earthq. Eng Struct Dyn. 33(8), 903-927 (2004)

6. T.S. Paraskeva, A, J Kappos, A.G. Sextos. Earthq. Engng Struct Dyn. 35, 1269-1293 (2006)

7. I. Muljati, P. Warnitchai. Civil Engg. Dim. 9 33-41 (2007)

8. T.S. Paraskeva, A.J. Kappos. Earthq. Eng. Struct Dyn 39(2), 211-222 (2010)

9. A.K. Chopra, R.K. Goel. Capacity-demand-diagram methods for estimating seismic deformation of inelastic structures: SDF system (Pacific Earthquake Engineering Research Center, Berkeley, 1999)

10. B.J. Mander, M.J.N. Priestley, R. Park, Fellow, ASCE. J. Struct. Eng. 114, 1827-1849 (1988)

11. B.J. Mander, M.J.N. Priestley, R. Park, Fellow, ASCE. J. Struct. Eng. 114(8), 1804-1828 (1988) 